OPEN ACCESS

Edited by:

Sviatlana Kamarova,

Curtin University, Australia

Reviewed by:

Peter Beattie,

The Chinese University of Hong Kong,

Hong Kong SAR, China

Shahrzad Goudarzi,

New York University, United States

*Correspondence:

Kai L

likaishuilingling@hotmail.com

Specialty section:

This article was submitted to

Personality and Social Psychology,

a section of the journal

Frontiers in Psychology

Received: 30 September 2021

Accepted: 29 December 2021

Published: 03 February 2022

Citation:

Yang L, Tang S and Li K (2022)

The Influence of the Disadvantaged

Mindset on System-Justifying Beliefs.

Front. Psychol. 12:787417.

doi: 10.3389/fpsyg.2021.787417

\section{The Influence of the Disadvantaged Mindset on System-Justifying Beliefs}

\author{
Lihua Yang ${ }^{1}$, Shujun Tang² and Kai Li ${ }^{3 *}$ \\ ${ }^{1}$ School of Foreign Languages, Jiangxi Normal University, Nanchang, China, ${ }^{2}$ School of Marxism, Jiangxi Normal University, \\ Nanchang, China, ${ }^{3}$ School of Psychology, Jiangxi Normal University, Nanchang, China
}

System justification theory holds that disadvantaged groups rationalize the current social system, even if it is unfavorable to them. Epistemic, relational, and existential needs are factors that explain this phenomenon. However, the literature has not yet examined and explained when disadvantaged groups no longer rationalize current social systems. This study uses a questionnaire survey method $(N=745)$ to study the moderating effect of collectivism on disadvantaged mindset and system-justifying beliefs. It found that collectivism can influence the predictive effect of disadvantaged mindset on systemjustifying beliefs. For people who scored low in collectivism, a disadvantaged mindset can significantly negatively predict system-justifying beliefs; for those who scored high in collectivism, a disadvantaged mindset no longer predicts system-justifying beliefs. Therefore, these results show that collectivist values are important for explaining system justification in disadvantaged groups. When collectivist values decline, the level of rationalization of the social system by disadvantaged groups also decreases.

Keywords: disadvantaged mindset, theory of system justification, collectivism, disadvantaged groups, social system

\section{INTRODUCTION}

That sometimes low-status, disadvantaged groups rationalize and defend existing social systems that are mostly unfavorable to them is paradoxical. Many studies have found that individuals tend to perceive unreasonable social systems as reasonable (Jost et al., 2012). For example, people with low incomes often oppose income redistribution (Kluegel and Smith, 1986), and women accept gender stereotypes and traditional gender roles (e.g., Glick et al., 2000). Low-income respondents and African Americans were more likely than others to support limitations to the rights of citizens and media representatives to criticize the government (Jost et al., 2003). To explain this phenomenon, scholars have formulated the system justification theory (Henry and Saul, 2006). According to this theory, people rationalize a system due to epistemic, relational, and existential (Jost and Banaji, 1994; van der Toorn and Jost, 2014; Jost, 2020). Despite the fact they dislike the situation initially, people will consciously or unconsciously convince themselves that the current social system is reasonable, or even selectively ignore some of its shortcomings (Blasi and Jost, 2006).

However, although some research evidence has been obtained to support of this theory, many studies have also found the opposite: disadvantaged groups are more dissatisfied with the social system (Yang et al., 2019). The circumstances under which people in disadvantaged positions no longer rationalize a system that is unfavorable to them are worthy of discussion (Owuamalam et al., 2019). The current study aims to explore the relationship between the mindset of disadvantaged individuals and system-justification beliefs. 
According to system justification theory, in addition to defending themselves and their group's interests, people tend to defend and rationalize the status quo (including the current social, economic, and political systems), sometimes at the expense of some of their own interests (Jost et al., 2004). According to this view, system justification is natural because people are psychologically motivated to rationalize the system (Jost, 2019). Disadvantaged people are unable to change their situation, so they employ a simple strategy of rationalizing the system to maintain cognitive balance. If they think that the system is unreasonable, they will experience cognitive dissonance; therefore, to maintain cognitive coordination, they are motivated to believe in the rationality of the system (Jost, 2017).

A disadvantaged mindset establishes itself when disadvantaged people recognize a painful reality for themselves (when compared to others). It is the individual's recognition of their strengths and weaknesses in competing to obtain a better life or higher social status than others (Li, 2020). Furthermore, it refers to the psychological tendency of individuals who usually feel disadvantaged in society, including feeling that their life is more difficult (Kuper and Kuper, 2001). Some research studies have found that system justification was positively associated with socioeconomic status (e.g., Lönnqvist et al., 2021). Compared to individuals with higher incomes, disadvantaged individuals feel that the system cannot meet their needs and that they are unable to change it. This evidence suggests that a disadvantaged mindset is negatively associated with system justification.

Collectivism places more importance on the group and society than on an individual's objectives (Oyserman et al., 2002). It can moderate the relationship between a disadvantaged mindset and system-justifying beliefs. On the one hand, individualism and collectivism are cultural dimensions that measure "the degree of interdependence a society maintains among individuals" (Hofstede, 1984, p. 83). Thus, the individualism/collectivism is a moderator of the relationship between use of e-learning systems and individual performance (Aparicio et al., 2016). On the other hand, to avoid social exclusion, people may be motivated to share their perception of reality with high system-justifiers (Cheung et al., 2011). These relational needs increase system-justification tendencies (Hess and Ledgerwood, 2014); thus, collectivism may strengthen the influence of a disadvantaged mindset on systemjustification beliefs.

The present study aims to investigate the effects of a disadvantaged mindset on system-justifying beliefs, and the potential moderating role of collectivism. It uses a questionnaire survey method to study the moderating role of collectivism. We developed the following research hypotheses for our study:

H1: For people who scored low in collectivism, a disadvantaged mindset can significantly negatively predict system-justifying beliefs.

$\mathrm{H} 2$ : For people who scored high in collectivism, a disadvantaged mindset does not predict system-justifying beliefs.

\section{MATERIALS AND METHODS}

\section{Research Participants}

$G^{*}$ Power (Faul et al., 2007) was used to conduct a power analysis with alpha $=0.05$, power $=0.95$, and a small effect size for a regression analysis of three predictors on a continuous outcome. To attain a small effect $\left(f^{2}=0.02\right)$ with those parameters, 652 participants were needed. A total of 745 students $(23.8 \%$ male, $74.8 \%$ female, $1.5 \%$ missing) at a university in Jiangxi Province participated in this study. Participants were 20.56 years of age on average $(\mathrm{SD}=1.76)$.

\section{Assessment Tools and Experimental Material}

The following assessment tools and experimental material were used in the current research:

(i) The disadvantaged mindset scale ( $\mathrm{Li}, 2020)$, which consists of eight items (e.g., "Even if I work hard, it is difficult to cope with the potential risks in life," "Compared with most people, I work harder but I am not more successful”), was used in this study. The evaluation was conducted using a seven-point scale ( 1 = completely disagree; 7 = completely agree), where higher scores indicated greater disadvantaged mindset. Cronbach's $\alpha$ for this scale was 0.78 .

(ii) The scale of system justification (Kay and Jost, 2003), which consists of eight items [e.g., "In general, I find society to be fair," "Our current society needs to be radically restructured(R)"], was used in this study. The items were evaluated on a seven-point scale ( $1=$ "completely disagree"; 7 = "completely agree"), where higher scores indicated stronger system-justifying beliefs. Cronbach's $\alpha$ for this scale was 0.82 .

(iii) The scale of collectivism (Yoo and Donthu, 2005), which consists of six items (e.g., "Individuals should sacrifice selfinterest for the group that they belong to," "Individuals should pursue their goals after considering the welfare of the group"), was used in this study. The items were evaluated on a seven-point scale ( 1 = "completely disagree"; 7 = "completely agree"). In this scale, higher scores indicated greater collectivistic tendencies. Cronbach's $\alpha$ for this study was 0.89 .

\section{Experimental Procedure}

All procedures in this study were performed in accordance with the standards of the Ethics Board of Jiangxi Normal University. All participants provided written informed consent before they participated in this study.

\section{Statistical Analysis}

Given that all the data were collected via questionnaire, we adopted the recommendations of MacKenzie and Podsakoff (2012) to control for the common potential biases in this method. Specifically, the data collection process was entirely anonymous, and after the data collection had been completed, we used Harman's single factor test to identify the potential level of 
TABLE 1 | Descriptive statistics and intercorrelations between variables ( $n=745)$.

\begin{tabular}{lrrccccr}
\hline & Mean & SD & $\mathbf{1}$ & $\mathbf{2}$ & $\mathbf{3}$ & $\mathbf{4}$ & $\mathbf{5}$ \\
\hline (1) Gender & 0.24 & 0.43 & 1 & & & & \\
(2) Age & 20.55 & 1.76 & -0.02 & 1 & & & \\
(3) Disadvantaged mindset & 3.80 & 0.87 & 0.001 & 0.01 & 1 & & \\
(4) Collectivism & 4.70 & 1.19 & -0.07 & 0.07 & $-0.12^{\text {** }}$ & 1 & \\
(5) SJB & 4.79 & 0.60 & -0.05 & $-0.08^{\star}$ & $-0.16^{\text {** }}$ & $0.38^{\text {** }}$ & 1
\end{tabular}

SJB, system-justifying belief; For gender, $0=$ female, $1=$ male. ${ }^{*} p<0.05$, ${ }^{* *} p<0.01$, and ${ }^{* *} p<0.001$.

common method variance. The results indicated that six factors had eigenvalues greater than 1 , and the variance of the first factor was $24.59 \%$ (i.e., less than $40 \%$, which is the lowest threshold commonly used for Harman's test).

\section{RESULTS}

\section{Results of Descriptive Statistics}

As shown in Table 1, disadvantaged mindset and systemjustifying beliefs were significantly negatively correlated $(r=-0.16, p<0.01)$, thus supporting Hypothesis 1 . In addition, a significant positive correlation between collectivism and system-justifying beliefs $(r=0.38, p<0.001)$ and a significant negative correlation between a disadvantaged mindset and collectivism $(r=-0.12, p<0.01)$ were found.

\section{Hypotheses Testing}

To examine the effects of a disadvantaged mindset and collectivism on system-justifying beliefs, we conducted a hierarchical regression analysis. First, gender and age were entered into the regression equation; second, disadvantaged mindset and collectivism were entered into the regression equation as predictors of system-justifying belief; third, the interaction term (disadvantaged mindset $\times$ collectivism) was entered. The results of this analysis are shown in Table 2.

Simple slope tests revealed that individuals with low collectivism (-1 SD) demonstrated a significant negative relationship between a disadvantaged mindset and systemjustifying beliefs $(B=-0.14, \mathrm{SE}=0.03, t=-4.51, p<0.001$, $95 \% \mathrm{CI}=[-0.20,-0.08])$. In contrast, individuals with high collectivism (+1 SD) did not display any significant relationship between disadvantaged mindset and systemjustifying beliefs $(B=-0.004, \mathrm{SE}=0.03, t=-0.12, p=0.90$, $95 \% \mathrm{CI}=[-0.07,0.06])$.

\section{DISCUSSION}

System justification theory emphasizes that system justification is essentially a motivational and goal-oriented psychological process (Jost, 2019), and that such beliefs are related to individual motivational social cognition (Wojcik et al., 2015). The present study found that a disadvantaged mindset is negatively correlated with system justification when collectivism is low, consistent with related research studies (e.g., Kraus and Callaghan, 2014; Kraus and Tan, 2015). In contrast, for people with high collectivism, a disadvantaged mindset does not predict system-justification beliefs. Our research broadens the scientific understanding of relationship between disadvantaged mindset and system-justification beliefs.

First, collectivism moderates the correlation between disadvantaged mindset and system-justification beliefs. This finding effectively explains some contradictory findings in the system justification theory literature describing how lower status groups will engage in more system justification than higher status groups. Collectivists are most likely to engage in self-enhancement along collectivist rather than individualist dimensions. Lower collectivists not inclined to rationalize systems (Sedikides et al., 2003). Thus, when people display high levels of collectivism, their systemjustification beliefs do not decrease although they have expended substantial effort yet have not been rewarded. This finding supports the hypothesis of Owuamalam et al. (2019) specifically that a greater sense of in-group membership among collectivists that leads them work harder to justify the system. In contrast, individualists would be less likely to identify with a collective system when they expend effort yet are not rewarded. Overall, the relationships between a disadvantaged mindset, system-justifying beliefs, and collectivism should be more thoroughly explored in future studies.

TABLE 2 | Hierarchical multiple regression on system-justifying belief $(n=745)$.

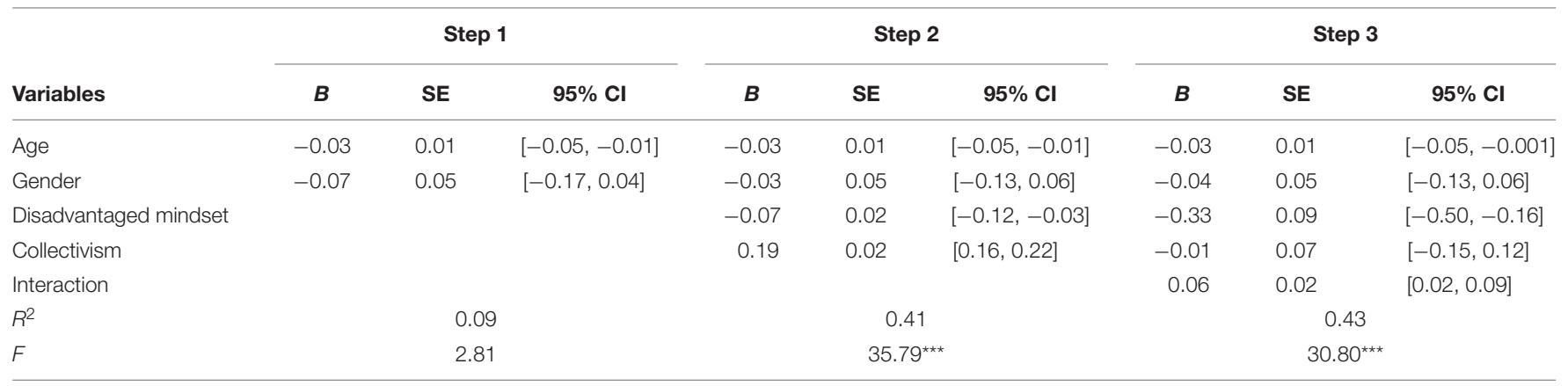

For gender, $0=$ female, $1=$ male. ${ }^{*} p<0.05,{ }^{* *} p<0.01$, and ${ }^{* * *} p<0.001$. 
Second, the disadvantaged mindset construct can help us better understand system justification theory. The disadvantaged mindset emphasizes how people's recognition that an individual has worked hard yet has not been rewarded ( $\mathrm{Li}, 2020)$, if they rationalize such systems, is influenced by other factors (such as collectivism and individualism). When individuals display low levels of collectivism, there was a significant negative relationship between a disadvantaged mindset and system-justifying beliefs. When they have strong collectivistic beliefs, a less disadvantaged mindset does not decrease the level of system-justifying belief. The negative correlation of disadvantaged mindset and systemjustification belief is weak, which suggests that the disadvantaged mindset is not a mere inversion of system justification. Thus, when people are high in disadvantaged mindset and high in system-justification beliefs, they might think that they are exceptionally unfortunate or incompetent, which may have deleterious effects on their mental health.

Third, this study has some limitations. Our results were obtained from a correlational analysis, therefore it cannot be determined whether disadvantaged mindset leads to lower collectivism and higher individualism, or if the relationship works in the inverse direction, or all factors are related to another unknown or unrecognized factor. Future research may benefit from exploring these relationships using controlled experiments conducted in the laboratory, or a moderation analysis. Future studies might examine people's early childhood environments to analyze how the disadvantaged mindset influences collectivism, individualism, and system-justifying beliefs.

\section{CONCLUSION}

Collectivism can influence the predictive effect of a disadvantaged mindset on system-justifying beliefs. For people scoring low in collectivism, the disadvantaged mindset significantly negatively predicts system-justifying beliefs; for those who scored high in collectivism, the disadvantaged mindset does not predict system-justifying beliefs. The results of this study show

\section{REFERENCES}

Aparicio, M., Bacao, F., and Oliveira, T. (2016). Cultural impacts on e-learning systems' success. Internet Higher Educ. 31, 58-70. doi: 10.1016/j.iheduc.2016. 06.003

Blasi, G., and Jost, J. T. (2006). System justification theory and research: implications for law, legal advocacy, and social justice. Calif. Law Rev. 94, 1119-1168. doi: 10.1093/acprof:oso/9780199737512.003.0003

Cheung, R. M., Noel, S., and Hardin, C. D. (2011). Adopting the system-justifying attitudes of others: effects of trivial interpersonal connections in the context of social inclusion and exclusion. Soc. Cogn. 29, 255-269. doi: 10.1521/soco.2011. 29.3.255

Faul, F., Erdfelder, E., Lang, A. G., and Buchner, A. (2007). G* Power 3: a flexible statistical power analysis program for the social, behavioral, and biomedical sciences. Behav. Res. Methods 39, 175-191. doi: 10.3758/BF03193146

Glick, P., Fiske, S. T., Mladinic, A., Saiz, J. L., Abrams, D., Masser, B., et al. (2000). Beyond prejudice as simple antipathy: hostile and benevolent sexism across cultures. J. Pers. Soc. Psychol. 79, 763-775. doi: 10.1037//0022-3514.79.5.763 that collectivist values are important for explaining system justification in disadvantaged groups. With a decline in collectivist values, rationalization of the social system by disadvantaged groups also decreases.

\section{DATA AVAILABILITY STATEMENT}

The original contributions presented in the study are included in the article/supplementary material, further inquiries can be directed to the corresponding author.

\section{ETHICS STATEMENT}

The studies involving human participants were reviewed and approved by the Ethics Board of Jiangxi Normal University. Written informed consent to participate in this study was provided by the participants' legal guardian/next of kin.

\section{AUTHOR CONTRIBUTIONS}

LY developed and validated the theoretical model. ST contributed to the data preparation and analysis and manuscript writing. KL expanded the theoretical model and manuscript writing. All authors wrote the manuscript and approved the final version of the manuscript for submission.

\section{FUNDING}

This study was financially sponsored by the National Social Science Fund Project (19BKS217).

\section{ACKNOWLEDGMENTS}

We thank SK and two reviewers for their comments.

Henry, P. J., and Saul, A. (2006). The development of system justification in the developing world. Soc. Justice Res. 19, 365-378. doi: 10.1007/s11211-006-0 $012-\mathrm{X}$

Hess, Y. D., and Ledgerwood, A. (2014). Bolstering system-justifying beliefs in response to social exclusion. Group Process. Intergroup Relat. 17, 494-508. doi: $10.1177 / 1368430213510572$

Hofstede, G. (1984). Culture's Consequences: International Differences in WorkRelated Values, Vol. 5. London: Sage. doi: 10.1016/0191-8869(85)90128-x

Jost, J. T. (2017). Working class conservatism: a system justification perspective. Curr. Opin. Psychol. 18, 73-78. doi: 10.1016/j.copsyc.2017.08.020

Jost, J. T. (2019). Aquarter century of system justification theory: questions, answers, criticisms, and societal applications. Br. J. Soc. Psychol. 58, 263-314. doi: $10.1111 /$ bjso. 12297

Jost, J. T. (2020). A Theory of System Justification. Cambridge, MA: Harvard University Press.

Jost, J. T., and Banaji, M. R. (1994). The role of stereotyping in system-justification and the production of false consciousness. Br. J. Soc. Psychol. 33, 1-27. doi: 10.1111/j.2044-8309.1994.tb01008.x 
Jost, J. T., Banaji, M. R., and Nosek, B. A. (2004). A decade of system justification theory: accumulated evidence of conscious and unconscious bolstering of the status quo. Polit. Psychol. 25, 881-919. doi: 10.1111/j.1467-9221.2004.00402.x

Jost, J. T., Chaikalis-Petritsis, V., Abrams, D., Sidanius, J., van der Toorn, J., and Bratt, C. (2012). Why men (and women) do and don't rebel: effects of system justification on willingness to protest. Pers. Soc. Psychol. Bull. 38, 197-208. doi: $10.1177 / 0146167211422544$

Jost, J. T., Pelham, B. W., Sheldon, O., and Sullivan, B. (2003). Social inequality and the reduction of ideological dissonance on behalf of the system: evidence of enhanced system justification among the disadvantaged. Eur. J. Soc. Psychol. 33, 13-36. doi: 10.1002/ejsp.127

Kay, A. C., and Jost, J. T. (2003). Complementary justice: effects of "poor but happy" and "poor but honest" stereotype exemplars on system justification and implicit activation of the justice motive. J. Pers. Soc. Psychol. 85, 823-837. doi: 10.1037/0022-3514.85.5.823

Kluegel, J. R., and Smith, E. R. (1986). Beliefs Without Inequality: Americans' View of What is and What Ought to be. Hawthorne, NJ: Aldine de Gruyter.

Kraus, M. W., and Callaghan, B. (2014). Noblesse oblige? Social status and economic inequality maintenance among politicians. PLoS One 9:e85293. doi: 10.1371/journal.pone.0085293

Kraus, M. W., and Tan, J. J. (2015). Americans overestimate social class mobility. J. Exp. Soc. Psychol. 58, 101-111. doi: 10.1016/j.jesp.2015.01.005

Kuper, A., and Kuper, J. (2001). Serving a new democracy: must the media 'speak softly'? Learning from South Africa. Int. J. Public Opin. Res. 13, $355-376$.

Li, K. (2020). The Study on the Formation Mechanism and Social Influence of Disadvantaged Mindset: A Social Quality-Based Perspective. Unpublished Doctoral dissertation. Nanjing: Nanjing Normal University.

Lönnqvist, J. E., Szabó, Z. P., and Kelemen, L. (2021). "The new state that we are building": authoritarianism and System-justification in an illiberal democracy. Front. Psychol. 12:703280. doi: 10.3389/fpsyg.2021.70 3280

MacKenzie, S. B., and Podsakoff, P. M. (2012). Common method bias in marketing: causes, mechanisms, and procedural remedies. J. Retail. 88, 542-555. doi: 10. 1016/j.jretai.2012.08.001

Owuamalam, C. K., Rubin, M., and Spears, R. (2019). Is a system motive really necessary to explain the system justification effect? A response to Jost (2019) and Jost, Badaan, Goudarzi, Hoffarth, and
Mogami (2019). Br. J. Soc. Psychol. 58, 393-409. doi: 10.1111/bjso.12 323

Oyserman, D., Coon, H. M., and Kemmelmeier, M. (2002). Rethinking individualism and collectivism: evaluation of theoretical assumptions and meta-analyses. Psychol. Bull. 128, 3-72. doi: 10.1037/0033-2909.128.1.3

Sedikides, C., Gaertner, L., and Toguchi, Y. (2003). Pancultural self-enhancement. J. Pers. Soc. Psychol. 84, 60-79. doi: 10.1037/0022-3514.84.1.60

van der Toorn, J., and Jost, J. T. (2014). Twenty years of system justification theory: introduction to the special issue on "Ideology and system justification processes."Group Process. Intergroup Relat. 17, 413-419. doi: 10.1177/ 1368430214531509

Wojcik, S. P., Hovasapian, A., Graham, J., Motyl, M., and Ditto, P. H. (2015). Conservatives report, but liberals display, greater happiness. Science 347, 1243 1246. doi: 10.1126/science.1260817

Yang, S.-L., Xu, B.-X., Yu, F., and Guo, Y.-Y. (2019). Revisiting the status legitimacy hypothesis: concepts, boundary conditions, and psychological mechanisms. J. Pacific Rim Psychol. 13:e20. doi: 10.1017/prp.2019.15

Yoo, B., and Donthu, N. (2005). The effect of personal cultural orientation on consumer ethnocentrism: evaluations and behaviors of US consumers toward Japanese products. J. Int. Consum. Market. 18, 7-44. doi: 10.1300/j046v18n01_ 02

Conflict of Interest: The authors declare that the research was conducted in the absence of any commercial or financial relationships that could be construed as a potential conflict of interest.

Publisher's Note: All claims expressed in this article are solely those of the authors and do not necessarily represent those of their affiliated organizations, or those of the publisher, the editors and the reviewers. Any product that may be evaluated in this article, or claim that may be made by its manufacturer, is not guaranteed or endorsed by the publisher.

Copyright (c) 2022 Yang, Tang and Li. This is an open-access article distributed under the terms of the Creative Commons Attribution License (CC BY). The use, distribution or reproduction in other forums is permitted, provided the original author(s) and the copyright owner(s) are credited and that the original publication in this journal is cited, in accordance with accepted academic practice. No use, distribution or reproduction is permitted which does not comply with these terms. 